\title{
Flood Modeling Using GIS and PCSWMM
}

\author{
Florife Liwanag $^{1,2, a, *}$, Daniel S. Mostrales ${ }^{1, b}$, Ma. Teresa T. Ignacio ${ }^{1, \mathrm{c}}$, \\ and Jerson N. Orejudos ${ }^{1, \mathrm{~d}}$
}

1 Mindanao State University - Iligan Institute of Technology, Iligan City, Philippines

2 University of Science and Technology of Southern Philippines, Cagayan de Oro City, Philippines

E-mail: aflorifedelarama@gmail.com (Corresponding author),bdsmostrales@gmail.com,

cmateresa.ignacio@g.msuiit.edu.ph, djerson.orejudos@g.msuiit.edu.ph

\begin{abstract}
Modeling flood inundation has become increasingly significant, especially for urban setting. Information on flood characteristics and accurate flow paths is significant for storm water management, hydrological modeling, hydrological data analysis, and vulnerability assessment. This paper employed geographic information system (GIS) to process the input data, RIDF curve to generate different design storm scenarios and PCSWMM to simulate the urban flooding of the Luinab catchment in Iligan City, Philippines. The results demonstrate the methodology for integrating GIS and flood model for analyzing the hydrological behavior of the catchment. The calibrated model clearly identified the area prone to flooding and predicts the influence of imperviousness on the hydrological behavior of the catchment. Improvement of the drainage system could be achieved by a) increasing the capacity of main canal and/or b) providing an additional outlet from identified areas that are prone to flooding.
\end{abstract}

Keywords: Flooding, geographic information system, stormwater management, river networks, urban drainage, urbanization.

ENGINEERING JOURNAL Volume 22 Issue 3

Received 12 January 2018

Accepted 15 June 2018

Published 28 June 2018

Online at http://www.engj.org/

DOI:10.4186/ej.2018.22.3.279 


\section{Introduction}

Human vulnerability to floods increased, caused by the alterations in land use patterns and acceleration in the population growth [1,2]. Identifying and locating inadequacies in drainage networks and producing surface runoff model would help in the reduction of man-made factors that contribute flooding in the area. Urban areas are characterized by the increase in imperviousness due to development.

With the advancement in the data collection method and modeling activities, there is an in-depth understanding how the drainage system works $[1,3,4]$. The use of geographic information system (GIS) technology improve the accuracy of determining flow paths and catchment boundaries. The use of GISbased software in the analyses and hydrological simulation of model provide speedy and reviewable assessment of the existing drainage system of the area. Incorporation GIS with hydrological model enables GIS users to conduct data management, thematic mapping, analyses, and simulation for scientific research and policy analysis. GIS provide data managers with the ideal computing platform for data inventory, parameter estimation, map creation and visualization [5].

Imperviousness obtained from land-use data and the spatial distribution of precipitation were processed through GIS. Hydrologic modeling analyses utilize the use of Personal Computer Storm Water Management Model (PCSWMM) [6], which provided the capability to model the impact of the drainage network structures on hydrologic response. Design storm test scenarios included 2-yr, 5-yr, 10-yr, and 25-yr flood. The calibrated model was able to predict the observed outputs with reasonable accuracy.

\section{Study Area}

The study area is a $4.531 \mathrm{~km}^{2}$ catchment located within Iligan City (Fig. 1) being served by the Luinab Creek, a tributary of the Mandulog River Basin comprising residential areas on the lower portion, and woodlands on the upper portion of the catchment.

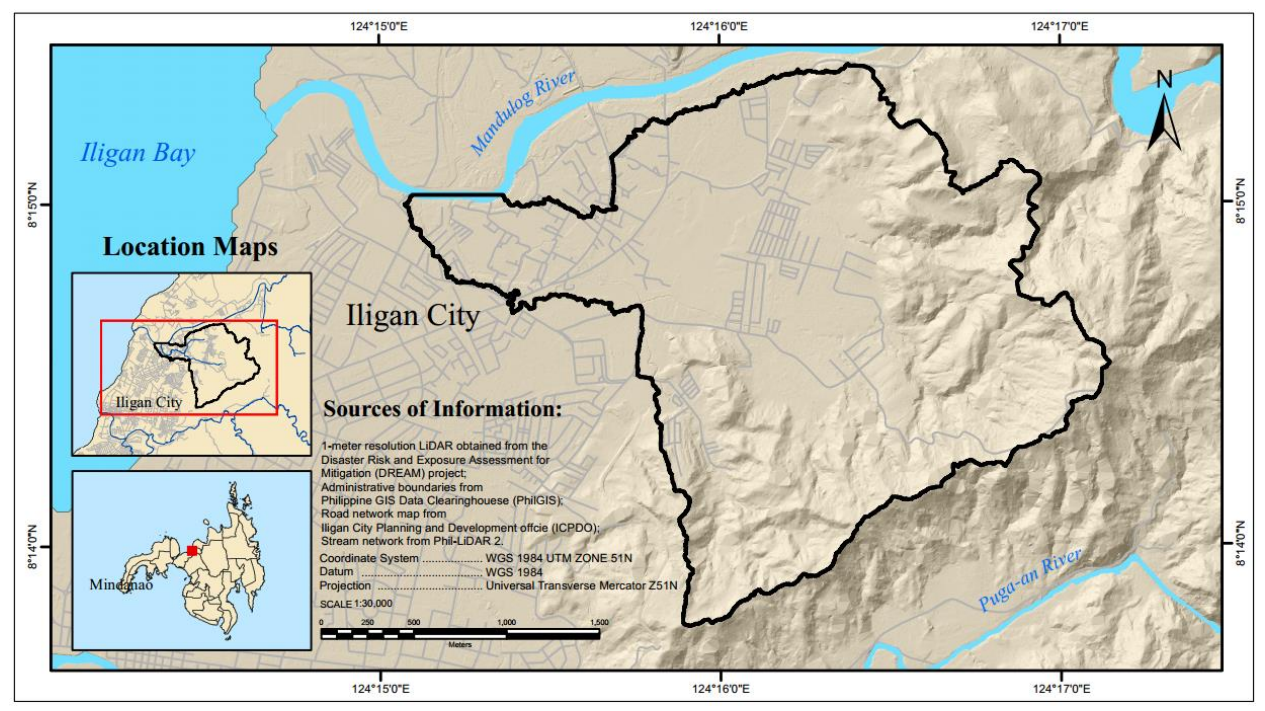

Fig. 1. Luinab catchment.

The catchment area is within the Cagayan de Oro synoptic station (Fig. 2) being operated and maintained by Philippine Atmospheric Geophysical and Astronomical Services Administration (PAGASA). This synoptic station is equipped with automatic rainfall gauge. 


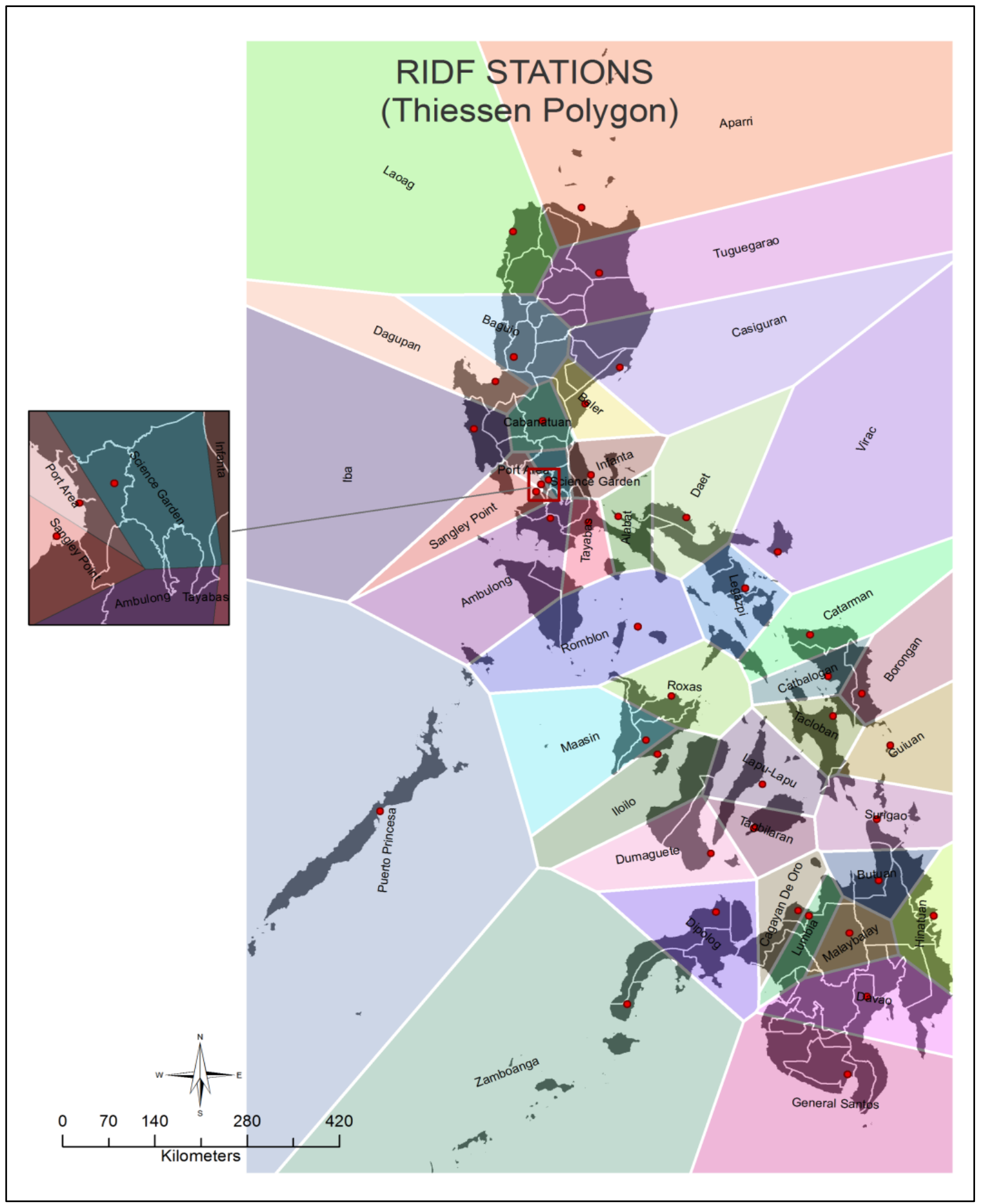

Fig. 2. Thiessen Polygon of RIDF Locations [7].

The Luinab Creek, a tributary of the Mandulog River basin was modeled in this study because of the availability of Light Detection and Ranging (LiDAR) data. A total of sixteen (16) subcatchments are delineated within the watershed. Rainfall in each subcatchment becomes overland surface runoff and flows are assumed to exit each subwatershed through a single outlet. Surface runoff flow entering the inlet is then routed through the connected channel or open canals depending on the location. Figure 3 shows the watershed with subcatchments and location of drainage lines. 


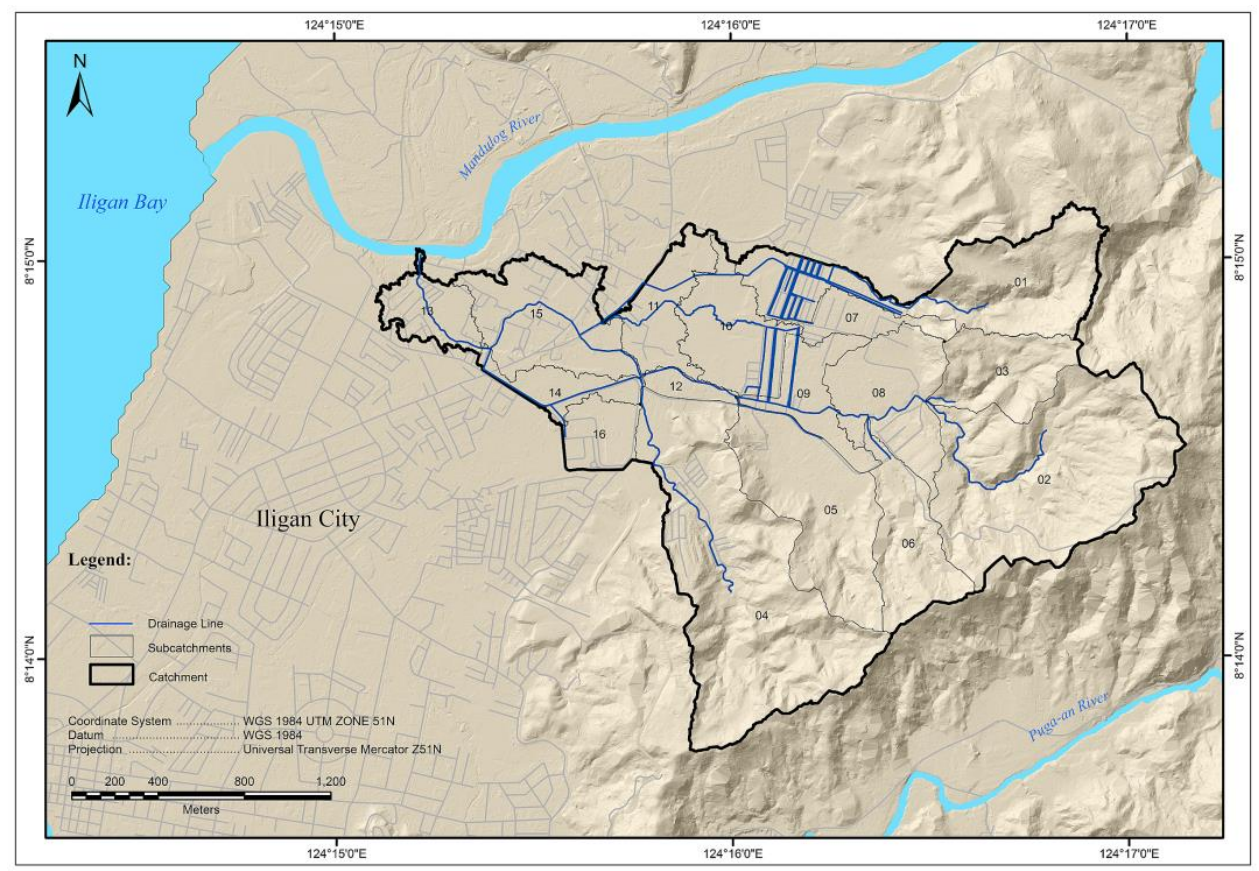

Fig. 3. Catchment and drainage network map.

\section{Instrumental Setup}

This section details the data collected and the processing applied to derive good-quality data. Field surveys were undertaken in April 2015 to supplement missing data for the study.

\subsection{Digital Elevation Model}

Digital elevation model (DEM) represents land elevation data, which are crucial for estimating storage volume of surface flooding [8]. Available LiDAR datasets used in the study include the LiDAR point cloud available in classified LiDAR Aerial Survey (LAS), 1-m resolution aerial imagery, and DEM. The LiDAR data was an output of the Philippine DREAM Program of UP TCAGP, a program funded by the Department of Science and Technology (DOST). Laser points were gathered over the study area using an Optech Airborne Laser Terrain Mapper (ALTM) Gemini and Pegasus LiDAR system set to acquire points at an average density of two points per $\mathrm{m}^{2}$. The reported accuracy of the LiDAR data is at $1 \mathrm{~m}$ root-meansquare error (RMSE) horizontal and $15 \mathrm{~cm}$ vertical. The survey was conducted on April 27-28, 2013.

\subsection{Rainfall Data}

Rainfall data drive the model and produce runoff, which means that an accurate estimation of rainfall data determines the success of the modeling effort. The estimated rainstorm intensity can be used to estimate the quantity of discharge. Rainfall data from the rain gauge stations near the catchment area were collected. There were four (4) rain gauge stations near the catchment area. However, there were only at least three (3) years of available rainfall data, from year 2012 to 2015. Calculation and simulation of flood discharges need longer range of available rainfall data.

In addition, the rainfall intensity is obtained from the RIDF curve. There is an RIDF curve available for Cagayan de Oro river basin in the report of Asian Development Bank (ADB) [9]. The RIDF curve was used to derive hyetographs for the design storm scenarios used. One of the most commonly used tools for the design of hydraulic and water resources engineering control structures [10]. Design storm test scenarios included 2-yr, 5-yr, 10-yr, and 25-yr flood. Their respective hyetographs were calculated using alternating block method from the RIDF curve and the area reduction curve. 


\subsection{Land Cover Map}

Land cover map was use for identifying the effects of land cover in the hydrologic behavior of the catchment. With the land cover characteristics, the pervious and impervious values of the catchment were converted into values and use for the calculation of peak discharge and simulation of flood model. The runoff coefficient in an urban catchment area is highly influenced by the impervious and pervious surface characteristics, as they participate a big part in generate discharge and affect the amount of rainwater entering a drainage system [11].

Land cover map (Fig. 4) generated by the study of dela Rama [12] were used for the study. Using object-based image analysis (OBIA), the available data were processed. LiDAR derivatives including intensity and number of returns were generated and the buildings footprint and buffered road network shapefiles were manually digitized. These layers, together with the digital terrain model (DTM), normalized digital surface model (nDSM), and orthophoto were processed using OBIA. The use of multiresolution segmentation was employed the creation of objects. Five (5) classes were defined including the built-up areas, fallow, grassland, road, and trees. Test and training (TTA) mask was created from the sample objects of the different classes employed. Using error matrix, the processing arrived to an overall accuracy of 0.978 and Kappa Index of Agreement (KIA) of 0.969.

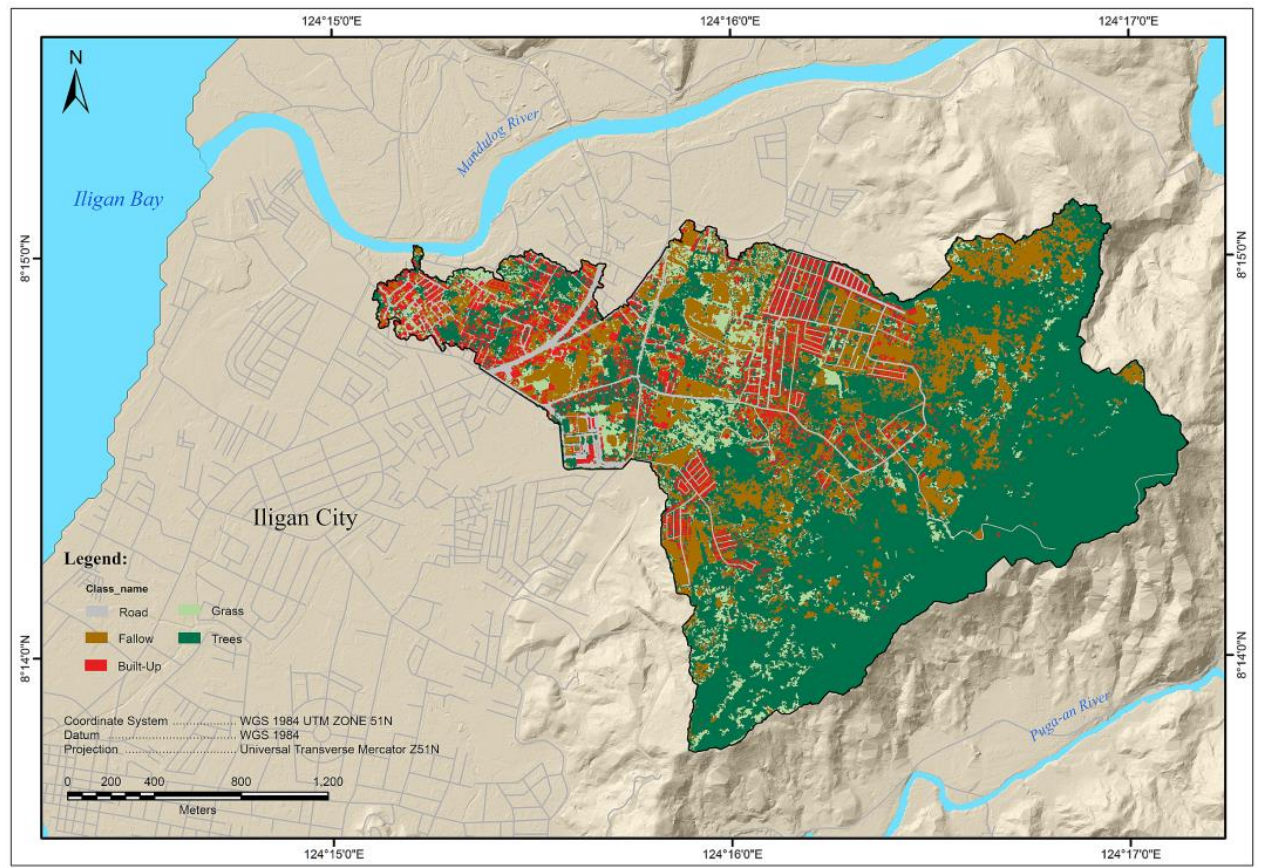

Fig. 4. Derived land cover map.

\subsection{Hydraulic Data}

There are three types of drainage network structures based on the different types of flow: man-made structures, such as pipes and channels, structures describing diffused overland flow (overland flow that has not passed through any structure), and structures describing concentrated overland flow (overland flow that resurfaced on the terrain, after passing through a structure or a number of structures). The drainage network database has the same form regardless of the structure that it represents but the values for derived parameters are calculated according to the physical properties of the structure that a record represents [13].

The parameters including the Green-Amp infiltration parameters, permeability, Manning's coefficient for channels and overland flow, entrance and exit loss coefficients were defined for the study. Most minor losses in a closed storm drain system will take place in a junction, usually a manhole structure, where the flow enters through one or more pipes and exits through a single conduit [14]. 
Table 1. Drainage Hydraulic Parameters [15].

\begin{tabular}{lcl}
\hline Description & Values & Unit \\
\hline Green-Amp Infiltration & & \\
\hline Ave. Capillary Suction & 298.8 & $\mathrm{~mm}$ \\
\hline $\begin{array}{l}\text { Saturated Hydraulic } \\
\text { Conductivity }\end{array}$ & 2 & $\mathrm{~mm} / \mathrm{hr}$ \\
\hline $\begin{array}{l}\text { Initial Moisture Deficit } \\
\text { for Soil }\end{array}$ & 0.267 & \\
\hline Permeability & 0.8 & $\mathrm{~cm} / \mathrm{hr}$ \\
\hline Manning's Coefficient & & \\
\hline Concrete pipe & 0.013 & \\
\hline Concrete Canals & 0.013 & \\
\hline $\begin{array}{l}\text { Open Channel - regular } \\
\text { section - dense grass and } \\
\text { weeds, depth of flow } \\
\text { materially greater than } \\
\text { weed height }\end{array}$ & & \\
\hline Entrance Loss Coefficient & 0.04 & \\
\hline $\begin{array}{l}\text { Inward Projecting } \\
\text { Sharp-Cornered }\end{array}$ & 0.8 & \\
\hline Slightly Rounded & 0.5 & \\
\hline Bell-Mouthed & 0.05 & \\
\hline Exit Loss Coefficient & 1.0 & \\
\hline
\end{tabular}

\section{Methodology}

With the use of digital terrain model, the catchment basin was delineated and the corresponding drainage line was generated. The result of delineation was validated in the field and from the existing maps for the catchment area. The drainage characteristics including the channel shape and dimension, geometry at nodes, and channel surface condition were also collected from the field.

The layers and its attributes for the PCSWMM were prepared in the ArcMap ${ }^{\mathrm{TM}}$ [16] environment. The 1-dimensional (1D) input layers for this study composed of four (4) layers including: junctions, conduits, outfall, and subcatchment boundaries. The layers prepared for the 2-dimensional (2D) input included the breakline, centerline, edge, obstruction and bounding layer. The attributes for these layers include the required input parameters, entity-specific computed results, and any additional user-defined attributes.

The layers were then calibrated based from the field data collected. During calibration process, only a limited number of parameters considered including sub-basin width, connected impervious percentage, watershed slope, stream Manning's roughness coefficient. After the simulation, the results of flood model were exported in the GIS environment and further classified. Results of the simulation were analyzed and compared with the flood inundation map from UP-TCAGP [7].

\section{Personal Computer Storm Water Management Model (PCSWMM)}

The 1-m resolution LiDAR DEM was used for the 2D DEM. Storm hyetograph generated from the RIDF curve were the input for SWMM rain gage time series. The overland flows were captured by inlets to the drainage network. The catchment model was run to estimate 2-yr, 5-yr, 10-yr, and 25-yr design hyetographs.

The 1D and 2D were incorporated with each other. Locations of the obstructions and outlet of each subcatchments were identified. The 2D cells were generated based from the attributes of the bounding polygon. 


\subsection{Parameter Estimation}

Parameters in a hydrological model are often classified as measured parameters or inferred parameters [17, 18]. Measured parameters indicate geometric characteristics of objects such as pipe size, surface elevation, catchment area, and manhole depth. Inferred parameters cannot be measured directly and are derived from models.

The areas of subcatchments are calculated in ArcGIS through the field calculation function. The values of slope, width, and percent imperviousness can also be measured using ArcGIS based on DEM data, subcatchment areas, and land-use maps. Because the areas automatically derived from the GIS using the computer are more accurate than those calculated by the traditional manual method, they can be considered constant during model calibration.

A runoff collection system can be represented as a network of links and nodes, where the links are conduits and the nodes are the points where the conduits join to one another [19]. Pipe and manhole parameters in the network models were measured and estimated during field data collection. The inferred parameters, including the roughness coefficients of pervious and impervious surfaces, the depression storage volumes of pervious and impervious areas, and the infiltration parameters defined by the GreenAmp infiltration coefficients estimated from empirical values.

\subsection{Design Storms}

Based from the derived design hyetograph, the intensity of the chosen design storms is derived from the calculated design hyetograph. The design hyetograph was calculated using the alternating block method. The intensity of the design storms based from calculated design hyetograph gathered has values: 36.02 , $48.48,56.41$, and $67.24 \mathrm{~mm}$ for design storms 2 -yr, 5-yr, 10-yr, and 25-yr.

\subsection{Calibration}

Urban flood inundation is challenging to validate and calibrate directly [20]. Manual calibration is labor intensive, especially when the catchment is large and complex [21]. Automatic parameter estimation and calibration methods have been implemented to overcome this difficulty.

The width of the overland flow was computed based from the subcatchments of the study. The percent of impervious area was calculated based from the generated land use map of the study. The depth of depression storage in pervious area control the sensitivity of runoff to precipitation. The larger the value, the bigger the storm before runoff will be observed.

\subsection{Flood Animation}

After simulating the model, the result was simulated and the animated results for the four (4) test scenarios were exported. The animation downloaded was for the 24 -hr storm duration of the test scenarios, using five (5) frames per second.

\section{Results and Discussion}

With the use of digital terrain model, the catchment basin was delineated and the corresponding drainage line was generated. The result of delineation was validated in the field and from the existing maps for the catchment area. The catchment garnered an area of $4.531 \mathrm{sq} . \mathrm{km}$. and sixteen (16) subcatchments.

It was observed that the subcatchment boundaries were more defined in the upper portion of the catchment due to sloping topography of the area. However, in the downstream area, due to the flat terrain characteristics coupled with the introduction of man-made drainage, there were false positive and false negative drainage network during delineation. The detected false positives were those natural areas without the presence of drainage but serves as detention area where the surface water flows naturally downward. On the other hand, false negatives were drainage lines with width that less than the resolution of the DEM.

Hydrologic modeling analyses utilize the use of PCSWMM, which provided the capability to model the impact of the drainage network structures on hydrologic response. The layers and its attributes for the PCSWMM were prepared in the ArcMap ${ }^{\mathrm{TM}}$ environment. Due to the fact that no surcharge or flooding event could be monitored, the PCSWMM software has been applied to a variety of test scenarios using 
design storms derived from the RIDF curve. The SWMM layers were then calibrated based from the field data collected. After the calibration, the data were simulated for the different test scenarios for 24 hours duration. After the simulation, the results of flood model were exported in the GIS environment and further classified to attain good visual representation. It was further classified according from the level of floods for the whole catchment. The inundation maps from the different test scenarios were assessed and compared.

Analysis showed that there is a comparable difference in the area for a specified water level. Table 2 shows the difference in areas for the depths assigned.

Table 2. Inundated areas at different test scenarios.

\begin{tabular}{crrrr}
\hline Water Depth & \multicolumn{1}{c}{ 25-YR } & \multicolumn{1}{c}{ 10-YR } & \multicolumn{1}{c}{ 5-YR } & \multicolumn{1}{c}{ 2-YR } \\
\hline$>5.000$ & 424.50 & 424.50 & 424.50 & 424.50 \\
$2.001-5.000$ & $3,771.86$ & $3,733.79$ & $3,634.61$ & $3,518.48$ \\
$1.001-2.000$ & $25,625.48$ & $24,289.14$ & $20,827.47$ & $19,473.54$ \\
$0.501-1.000$ & $86,206.53$ & $81,469.63$ & $70,106.34$ & $48,652.77$ \\
$0.201-0.500$ & $114,318.40$ & $117,369.30$ & $109,481.47$ & $99,211.96$ \\
$0.101-0.20$ & $83,415.97$ & $386,579.74$ & $73,317.12$ & $363,460.82$ \\
$0.001-0.100$ & $382,217.19$ & $77,375.16$ & $372,846.04$ & $76,521.95$ \\
\hline Total & $695,979.92$ & $691,241.26$ & $650,637.55$ & $611,264.02$ \\
\hline
\end{tabular}

For depth range less than 0.201, 2-yr and 10-yr design storms showed similar trend and design storm 5$\mathrm{yr}$ and $25-\mathrm{yr}$ showed similar trend. For water depth range of $0.201 \mathrm{~m}$ to $5.0 \mathrm{~m}$, all the test scenarios showed the same trend in terms to change in inundated areas. For depth more than $5.0 \mathrm{~m}$, test scenarios showed uniform inundated areas.

The flood inundation map derived from the simulation for the $25-\mathrm{yr} 24$ hours duration were also compared with the 25-yr from the DREAM Program. Difference in the area covered from the inundation was observed for the two (2) maps. There was a significant difference in the inundated area for two (2) results. Table 3 shows the tabulated values for the two (2) inundation maps from DREAM and from the study. There was a difference in the inundated area for the two studies.

Table 3. 25-YR Storm Inundated Areas.

\begin{tabular}{lrr}
\hline Water Depth & DREAM Map & \multicolumn{1}{r}{ 25-YR } \\
\hline$>5.000$ & $272,475.00$ & 424.49 \\
$2.001-5.000$ & $569,250.00$ & $3,771.86$ \\
$1.001-2.000$ & $833,850.00$ & $25,625.48$ \\
$0.501-1.000$ & $1,233,450.00$ & $86,206.53$ \\
$0.201-0.500$ & $1,606,275.00$ & $114,318.40$ \\
$0.101-0.20$ & $994,050.00$ & $83,415.97$ \\
$0.001-0.100$ & $3,790,575.00$ & $382,217.19$ \\
\hline Total & $5,509,350.00$ & $695,979.92$ \\
\hline
\end{tabular}

Analysis showed that there is a comparable difference in the area for a specified water level. For all the design frequencies simulated, there was a uniform area where the maximum depth of $5 \mathrm{~m}$ occurred. For water depth range of $0.201 \mathrm{~m}$ to $>5.000 \mathrm{~m}$, all the test scenarios shows the same trend. For all test scenarios, there were an increase in inundated area.

Simulation time for different test scenarios was tabulated (Table 4). Simulation results showed that for designs storms 2-yr, 5-yr, and 10-yr, and 25-yr, simulation took 6.48 hours, 6.32 hours, 6.77 hours, and 9.57 hours, respectively. Results of the SWMM model analysis (Fig. 5(a), (b), (c), (d)) suggest the areas prone to flooding and areas were surface runoff occurs. For depth range less than 0.201, 2-yr and 10-yr design storms showed similar trend and design storm 5-yr and 25-yr showed similar trend. For water depth range 
of $0.201 \mathrm{~m}$ to $5.0 \mathrm{~m}$, all the test scenarios showed the same trend in terms to change in inundated areas. For depth more than $5.0 \mathrm{~m}$, test scenarios showed uniform inundated areas.

Table 4. Model Simulation Time.

\begin{tabular}{cccc}
\hline Event & Duration & Model & Simulation Time \\
\hline 2-year return period & 24 hours & 1D/2D & 6 hours 29 minutes \\
5-year return period & 24 hours & 1D $/ 2 \mathrm{D}$ & 6 hours 19 minutes \\
10-year return period & 24 hours & 1D $/ 2 \mathrm{D}$ & 6 hours 23 minutes \\
25-year return period & 24 hours & 1D/2D & 9 hours 34 minutes \\
\hline
\end{tabular}

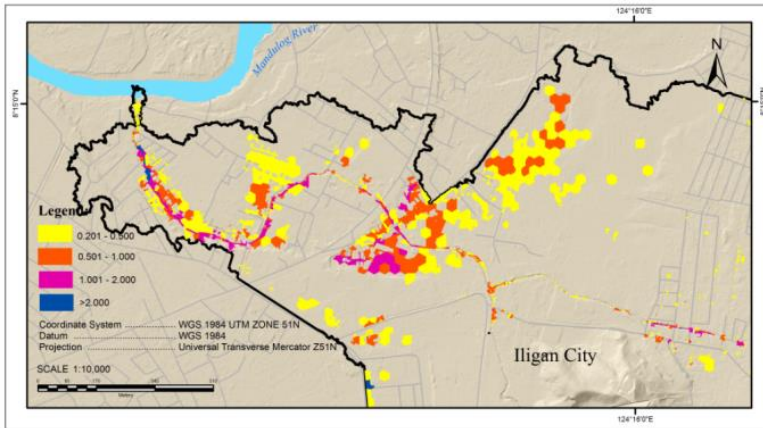

(a)

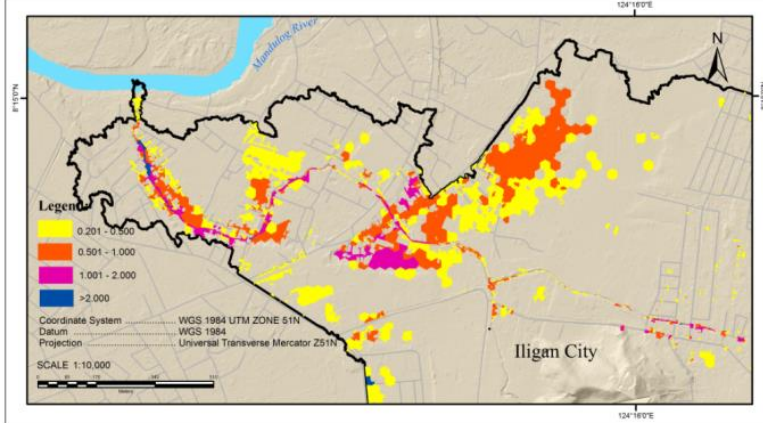

(c)

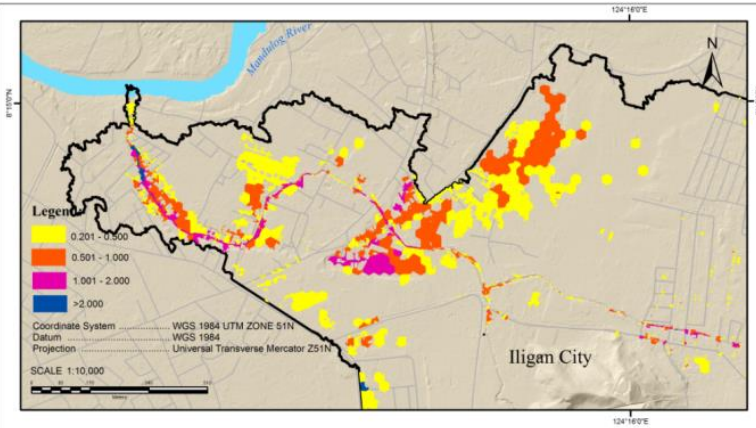

(b)

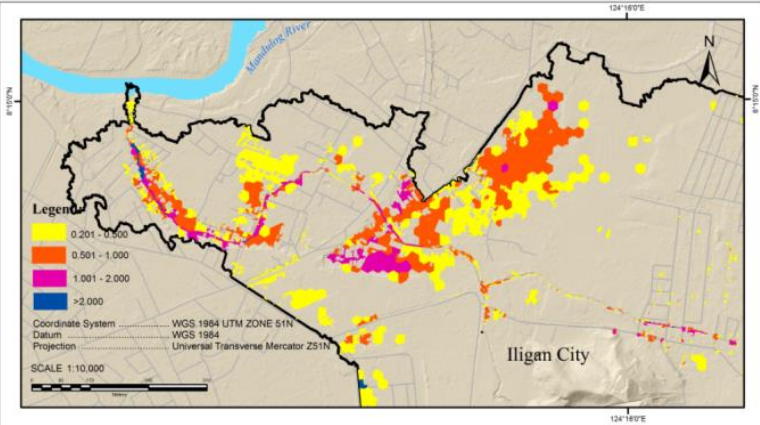

(d)

Fig. 5. (a) 2-yr 24-hrs Flood Inundation Map; (b) 5-yr 24-hrs Flood Inundation Map; (c) 10-yr 24-hrs Flood Inundation Map; (d) 25-yr 24-hrs Flood Inundation Map.

The flood inundation maps derived were compared with the published inundation map for 25-yr flood (Fig. 6). Results showed that although the 25 -yr inundation map showed the effects of rainfall for the Mandulog River, the trend of the inundated areas in terms of depth is similar with the trend of the inundate areas with the 25-yr design storm simulated on the study.

In the study, it was assumed that the water level at the outfall is not affected by tidal influence and backflow. It was also assumed that the catchment was not affected by the overflowing water from the Mandulog River for the 25-yr design storm. This would mean that the catchment is not affected with the overflowing of the neighboring catchments at storms with 25-yr return period. The outfall is affected with the backflow of water, especially during storms with high frequencies.

It was found out that as the rainfall frequency increases, there was also an increase of water depth within the catchment. The flood inundation map derived from the simulation for the $25-\mathrm{yr} 24$ hours duration was compared with the flood inundation map for the 25-yr from the DREAM Program. Figure 6 presented the two maps. 


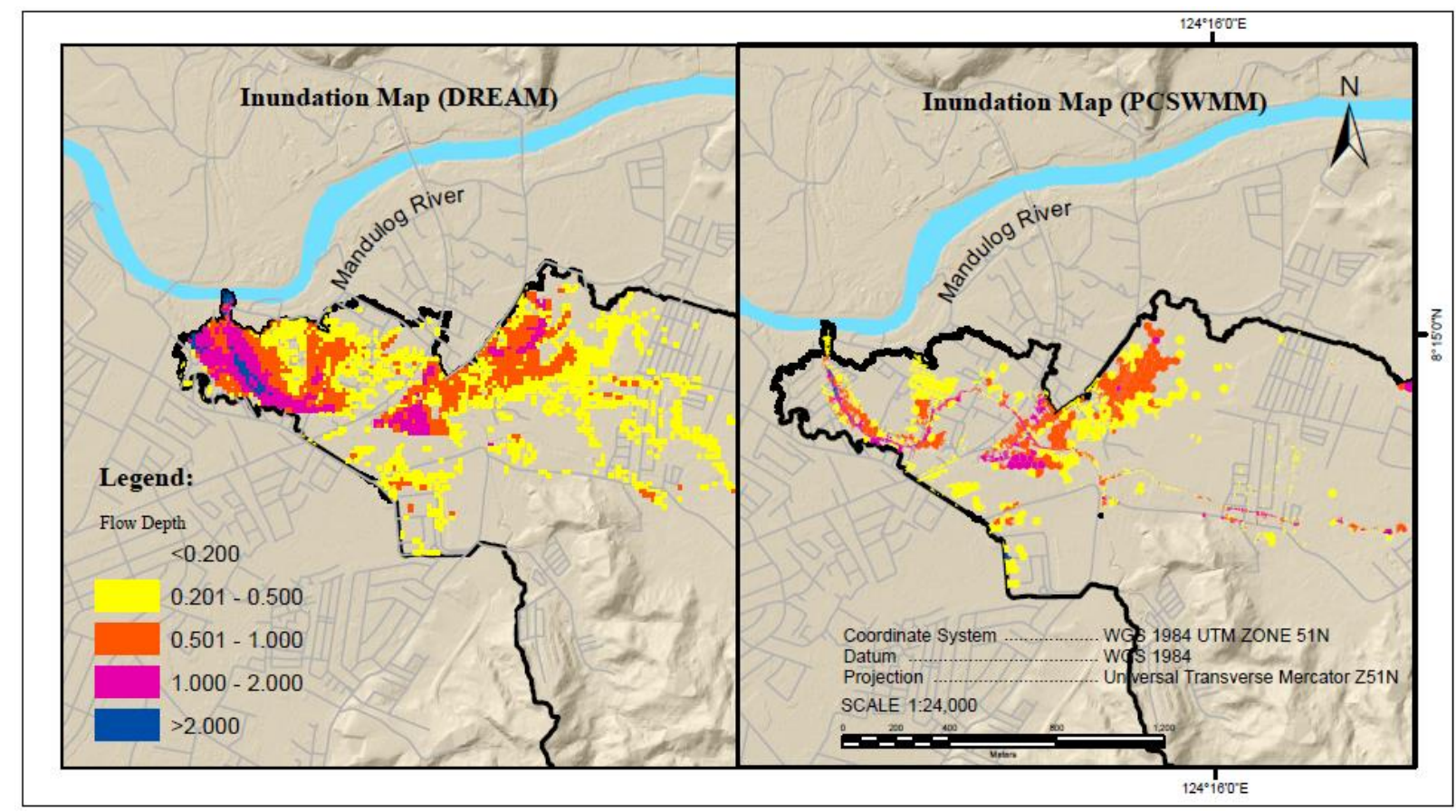

Fig. 6. DREAM Flood Inundation vs. PCSWMM Flood Inundation.

\section{Summary}

The results demonstrate the methodology for integrating GIS and flood model for analyzing the hydrological behavior of the catchment. The calibrated model clearly identified the area prone to flooding and predicts the influence of imperviousness on the hydrological behavior of the catchment. Improvement of the drainage system could be achieved by a) increasing the capacity of main canal and/or b) providing an additional outlet from identified areas that are prone to flooding.

\section{Acknowledgement}

This work was supported by the Department of Science and Technology of the Philippines through the Phil-LiDAR 2 project of MSU - IIT. The LiDAR dataset for this research was kindly provided for by the Philippine DREAM Program, road network from PhilGIS, and drainage network from Iligan City Planning and Development Office. Special thanks are given to the project partners in University of the Philippines Diliman Phil-LiDAR 2 (Melanie Gaspa and Dominic Aloc), research co-workers Anacita Tahud, Al Mon Dahan, Oliver Arriesgado, and Civil Engineering students of MSU - Iligan Institute of Technology.

\section{References}

[1] J. D. Miller, H. Kim, T. Kjeldsen, J. Packman, S. Grebby, and R. Dearden, "Assessing the impact of urbanization on storm runoff in a peri-urban catchment using historical change in impervious cover," Journal of Hydrology, vol. 515, pp. 59-70. Apr. 2014.

[2] L. Nie, "Flooding analysis of urban drainage systems," Ph.D. dissertation, Engineering Science and Technology, Norwegian University of Science and Technology, Trondheim, Norway, Oct. 2003.

[3] C. Maksimovic, IHP-V 1 Technical Documents in Hydrology 1 No. 40, Vol. III. UNESCO, Paris, 2001.

[4] B. C. Phillips, S. Yu, G. R. Thompson, and N. de Silva, "1D and 2D modelling of urban drainage systems using XP-SWMM and TUFLOW," in 10 th International Conference on Urban Drainage, Copenhagen, Denmark, 21-26 Aug. 2005.

[5] D. Z. Suia and R. C. Maggio, "Integrating GIS with hydrological modeling: practices, problems, and prospects," Computers, Environment and Urban Systems, vol. 23, no. 1, pp. 33-51, 1999. 
[6] Computational Hydraulics International (CHI), PCSWMM Professional 2D. Guelph, Ontario, Canada, 2016. [Online]. Available: www.chiwater.com [Accessed July 22, 2015]

[7] University of the Philippines, Training Center for Applied Geodesy and Photogrammetry (UP TCAGP), "Flood forecasting and flood hazard mapping for Cagayan de Oro River Basin," Disaster Risk and Exposure Assessment for Mitigation (DREAM), DOST-Grants-In-Aid Program, 2015.

[8] C. Apirumanekul and O. Mark, "Modelling of urban flooding in Dhaka City," in 4th DHI Software Conference, Helsingør, Denmark, 2001.

[9] Asian Development Bank (ADB), "Philippines: Master plan for the Agusan River basin," ADB Technical Assistance Consultant's Report, CTI Engineering International Co. Ltd./Halcrow/Woodfiled Consultants, Inc., Philippines, 2008.

[10] R. E. Antigha and N. M. Ogarekpe, "Development of intensity duration frequency curves for Calabar Metropolis, South-South, Nigeria," The International Journal of Engineering and Science (IJES), vol. 2, no. 3, pp. $39-42,2013$.

[11] M. Aktaruzzaman, "High resolution digital surface model (DSM) to support modelling of urban flooding," Ph.D. dissertation, Dept. of Civil Engineering, University of Kaiserslautern, Bundesland, Rhineland-Palatinate, 2011.

[12] F. P. dela Rama, "Urban drainage network modeling using Geographic Information Systems (GIS) and Storm Water Management Model (SWMM): A case study of selected barangays in Iligan City," Dept. of Civil Engineering, MSU-IIT, Iligan City, Philippines, 2011.

[13] D. Djokic and D. R. Maidment, "Terrain analysis for urban stormwater modeling," Hydrological Processes, vol. 5, pp. 115-124, 1991.

[14] W. H. Frost, "Minor loss coefficients for storm drain modeling with SWMM," Journal of Water Management Modeling, vol. 4, pp. R225-23, 2006.

[15] Water Research Center. (2014). Estimation of Green-Ampt Infiltration Parameters [Online]. Available: http://www.water-research.net/ [Accessed: 15 January 2016]

[16] Environmental Systems Research Institute (ESRI), ArcGIS Desktop: Release 10. Redlands, CA: Environmental Systems Research Institute, 2011. [Online]. Available: http://www.esri.com/ [Accessed: 11 November 2014]

[17] P. Yu, T. Yang, and S. Chen, "Comparison of uncertainty analysis methods for a distributed rainfallrunoff model," Journal of Hydrology, vol. 244, pp. 43-59, 2001.

[18] K. Choi and J. Ball, "Parameter estimation for urban runoff modeling," Urban Water, vol. 4, pp. 31-41, 2002.

[19] W. James, L. A. Rossman, and W. R. C. James, User's Guide to SWMM 5, 13th ed. Guelph, Ontario, Canada: CHI Press Publication, Nov. 2010.

[20] J. Chen, A. A. Hill, and L. D. Urbano, "A GIS-based model for urban flood inundation," Journal of Hydrology, vol. 373, pp. 184-192, Apr. 2009.

[21] Z. Dongquan, C. Jining, W. Haozheng, T. Qingyuan, C. Shangbing, and S. Zheng, "GIS-based urban rainfall-runoff modeling using an automatic catchment-discretization approach: a case study in Macau," Environmental Earth Sciences, vol. 9, pp. 465-472, 2009. 